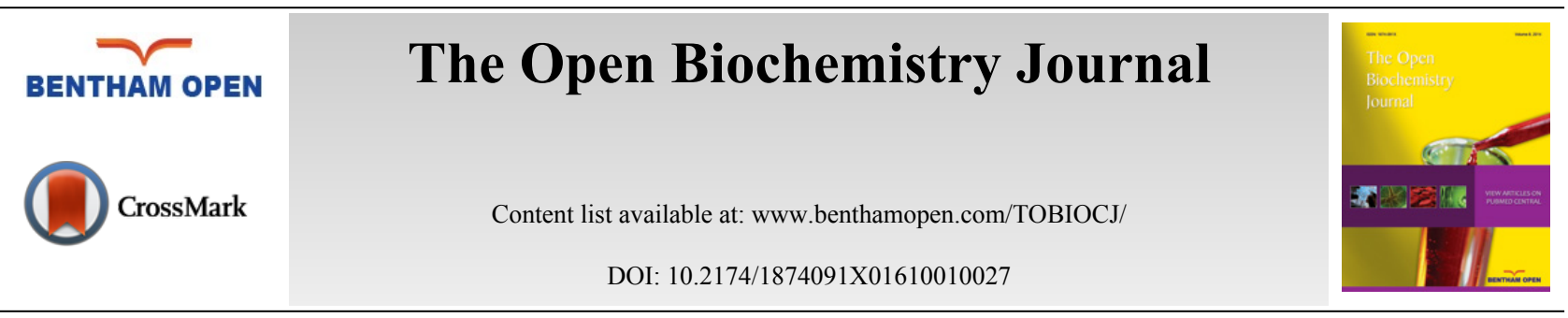

\title{
Interrelation of Glycemic Status and Neuropsychiatric Disturbances in Farmers with Organophosphorus Pesticide Toxicity
}

\author{
Farrukh Jamal", Quazi S. Haque and Sangram Singh \\ Department of Biochemistry, Dr. Ram Manohar Lohia Avadh University, Faizabad-224001, India
}

Received: September 11, 2014

Revised: January 14, 2016

Accepted: January 15, 2016

\begin{abstract}
:
Background:

Diverse group of agro-chemicals are indiscriminately sprayed by the farmers for pest control to enhance crop yield. About 25 million agricultural workers in the developing world suffer from at least one episode of poisoning each year, mainly by anticholinesteraselike organophosphates (OPs).
\end{abstract}

\section{Objective:}

The present study was aimed to establish the OP toxicity in 187 occupationally exposed pesticide sprayers of mango plantation in rural Malihabad, Lucknow, in terms of neuro-cognitive impairment, mental health status, clinical symptoms, diabetes, and hematological factors.

\section{Method:}

The exposed group was compared to 187 pesticides-unexposed normal healthy persons engaged in normal usual agricultural work (age, sex and education corresponding to age group of selected subject group) from Rural Malihabad, Lucknow (India). Neurocognitive impairment was measured using the Subjective Neurocognition Inventory and mental health status using the General Health questionnaire-28. The subjects were also tested for biochemical and enzymatic parameters.

\section{Results:}

The exposed farmers showed alterations in enzymatic and clinical parameters. While the rates of anxiety / insomnia and severe depression were also significantly higher in the pesticide sprayers, disorders affecting psychomotor speed, selective attention, divided attention, verbal memory, nonverbal memory, prospective memory, spatial functioning, and initiative/energy were all lower in the sprayers. Pesticide sprayers showed a number of clinical symptoms like eczema, saliva secretion, fatigue, headache, sweating, abdominal pain, nausea, superior distal muscle weakness, inferior distal muscle weakness, hand tingling and etc. which all significantly correlated with the number of working years.

\section{Conclusion:}

These findings suggested that farmers who work with OPs are prone to neuro-psychological disorders and diabetes.

Keywords: Agriculture, cognitive disorders, diabetes mellitus, organophosphorus poisoning, pesticide sprayers.

\section{INTRODUCTION}

Pesticides are extensively used throughout the world and, in recent years, their use has increased considerably. India is basically an agricultural country. Nearly $70 \%$ of its population lives in rural areas. Pesticides are biocides capable of

\footnotetext{
* Address correspondence to this author at the Department of Biochemistry, Dr. Ram Manohar Lohia Avadh University, Faizabad-224001, U.P. (India); Fax: +91-05278-246330; E-mail: farrukhrmlau@gmail.com
} 
killing all forms of life. The primary occupation of rural population is agriculture. A diverse group of agro-chemicals are indiscriminately sprayed by the farmers for the pest control to save the crop. These agro-chemicals are popularly known as pesticides which have been broadly classified into organo-phosphorus, organo-chlorine, carbamates and pyrethroids. The most commonly sprayed pesticides are organo-phosphorus (OP) insecticides which are very powerful neurotoxins resulting in neurotoxicity on acute or chronic exposure [1]. India is the largest manufacturer of basic pesticides in Asia and ranks $12^{\text {th }}$ globally. Insecticides account for $75 \%$ of India's total pesticide consumption, followed by fungicides (at 12\%) and herbicides (at 10\%) [2]. A WHO task group has lately estimated that the number of pesticide poisoning may soar to three million cases and result in more than 250,000 deaths [3]. However, the problem is more complicated according to a recent survey in Asia, indicating that as many as 25 million farmhands suffer episodic poisoning every year [4]. Anticholinesterase (AChE) compounds, organophosphates and carbamates (CMs) are for the most part used in farming, as well as in human and veterinary medicine. These compounds can affect mammalian systems by inhibiting acetylcholinesterase at the synapses and muscular junctions, which may result in hypercholinergic preponderance. Apparently, the mechanisms causing brain, muscle or other organ damage by OPs are mostly related to a change in oxidant-antioxidant balance, which in turn results in free radical-mediated injury, as supported by many studies [5 - 10]. Careless use of pesticides like OPs may cause diverse health complications by upsetting the nervous, endocrine, reproductive, and immune systems [11, 12]. In both types of diabetes, long-term increase in glucose starts complications in target organs. As the production of reactive oxygen species (ROS) and reactive nitrogen species (RNS) rises, so does oxidative stress [13]. This, possibly together with the rise of fatty acid, favours the adverse effects of high glucose.

Type 2 diabetes is more complex than Type 1 and has two known mechanisms. One is insulin resistance, in which insulin is less active on peripheral tissues, and the other one is insulin deficiency, in which pancreatic beta cells cannot release insulin properly. Genes and environment are responsible for these malfunctions [13]. It is estimated that the number of people who suffer from type 2 diabetes will rise from 171 million in 2000 to 366 million in 2030 [13]. Many studies corroborate that OP exposure might contribute to type 2 diabetes [14, 15]. Although the overall evidence of neurological and neurobehavioral effects of long-term OP exposure are thought to be small, it is not that difficult to find some [16, 17]. Environmental agents which have neuro-toxic effects may cause a wide variety of problems, including mental retardation and disability as well as subtle changes in performance, which are mainly related to exposure time and the amount of the chemical agent [18]. These indicate that a correlation exists between exposure to OP and mitochondrial toxicity, especially in the central nervous system [19, 20]. OPs are known to inhibit acetyl cholinesterase (AChE), but they can also act through non-cholinergic pathways such as acylpeptide hydrolase [21, 22].

Acylpeptide hydrolase is more sensitive to dichlorvos than AChE, the parent compound of metrifonate, a therapeutic agent used in the treatment of cognitive impairment and Alzheimer's disease. However, little is known about the direct action of acylpeptide hydrolase on cognitive processes and the physiological and molecular effect of OPs [22]. Moreover, OPs can inhibit neuropathy target esterase (NTE) to cause paralysis of lower-limbs and a distal injury to long nerve axons [23]. Main neuro-toxic effects in humans caused by OPs include the cholinergic syndrome, the intermediate syndrome, delayed polyneuropathy, and chronic neuropsychiatric disorder [17, 24]. Acute health effects are very well known, but the long-term effects of chronic low-level exposure are still to be evaluated [12, 13, 25, 26]. The aim of the present study is to determine neuro-cognitive impairment, mental health status, clinical symptoms, diabetes incidence, and haematological disorders in sprayers occupationally exposed to OP pesticides in rural Malihabad, Lucknow India.

\section{MATERIALS AND METHODS}

This comparative cross-sectional study included 374 subjects, 252 men and 122 women. All gave informed consent before enrolment, and the study protocol was approved by the Institutional Review Board. A summary of demographic data on workers and control subjects is shown in Table 1. The first group included 187 (16 to 80-year-old) pesticide sprayers in mango plantation of Malihabad, Lucknow (India). Control subjects consisted of 187 age-matching workers from the same village who were not engaged in any agricultural work and had no history of job related exposure to OP pesticides. Information on working history, socioeconomic status (salary, education), and lifestyle (smoking, alcohol consumption, drug use, vitamin or antioxidant supplementation, and dietary habits) were obtained at an interview with expert examiner. Neuro-cognitive impairment was measured using the Subjective Neuro-cognition Inventory and mental health status was evaluated using the General Health Questionnaire [18] as described elsewhere [27, 28]. All subjects underwent a thorough clinical examination for any signs or symptoms of chronic illnesses. Subjects with chronic illnesses or receiving drug or radiation therapy, consuming alcohol, drugs of abuse, or antioxidant 
supplementation or subjects exposed to toxins other than OPs at screening were excluded from the study. Blood samples were collected from the subjects throughout the spraying season on Saturday's forenoon between 7 and 8 prior to work and following parameters were measured. Blood was tested for fasting blood glucose, blood urea nitrogen, cholesterol, triglycerides, creatinine, high-density lipoprotein, aspartate aminotransferase, alanine aminotransferase, and alkaline phosphatase.

Table 1. Summary of demographic data in pesticide sprayers and control subjects.

\begin{tabular}{|c|c|c|c|c|}
\hline Subjects & Sex & $\begin{array}{c}\text { Sprayers } \\
(n=187)\end{array}$ & $\begin{array}{c}\text { Controls } \\
(n=187)\end{array}$ & $p$ Value* \\
\hline Age/years & & $37.84 \pm 12.41$ & $37.05 \pm 10.69$ & 0.48 \\
\hline \multirow[t]{2}{*}{ Sex } & Male & 126 & 126 & - \\
\hline & Female & 61 & 61 & - \\
\hline Work history / years & & $9.88 \pm 7.72$ & - & - \\
\hline Smoking / years & & $0.38 \pm 2.45$ & $1.37 \pm 5.3$ & 0.026 \\
\hline Smoking / Cigarette / day & & $0.64 \pm 3.75$ & $1.07 \pm 4.1$ & 0.27 \\
\hline
\end{tabular}

Data represent mean \pm SD. ${ }^{*}$ Two-sided Student's t-test.

\subsection{Measurement of Acetyl Cholinesterase}

Serum acetyl cholinesterase was measured using the Accucare kit method of Knedel et al. (1967) [29].

\subsection{Measurement of SGOT (AST) and SGPT (ALT)}

Liver and kidney functions tests were measured using a fully automated biochemistry analyzer (Eurolyser) on the same day of sample collection. The transaminases SGOT (AST) and SGPT (ALT) were measured by the UV-kinetic method [30]. The conversion of NADH to $\mathrm{NAD}^{+}$in both transaminase reactions was measured at $340 \mathrm{~nm}$, as the rate of decrease in absorbance.

\subsection{Measurement of Serum Alkaline Phosphatase}

Serum alkaline phosphatase was measured by the King Armstrong method using Span diagnostics kit [31]. Phenol is released by an enzymatic hydrolysis from disodium phenyl phosphate under defined conditions of time, temperature, and $\mathrm{pH}$. The phenol reacts with 4- aminoantipyrine in the presence of alkaline oxidizing agent to produce a red compound measured at $520 \mathrm{~nm}$ against a reagent blank. Color development is rapid and stable for at least one hour in bright light. Sodium hydroxide is added immediately after incubation to raise the $\mathrm{pH}$ and stop the reaction. Potassium ferricyanide is the oxidizing agent and sodium bicarbonate is added to provide an alkaline medium.

\subsection{Measurement of Blood Urea}

Blood urea was measured by glutamate dehydrogenase method [32]. Blood urea is decomposed by urease to form ammonia and carbon dioxide. Ammonia combines with 2-oxoglutarate in presence of glutamate dehydrogenase and $\mathrm{NADH}$ to form L-glutamate and $\mathrm{NAD}^{+}$. The rate of $\mathrm{NAD}^{+}$formation was measured at $340 \mathrm{~nm}$ and was directly proportional to blood urea. Each molecule of urea hydrolyzed liberates two molecules of NAD ${ }^{+}$.

\subsection{Measurement of Serum Creatinine, Blood Glucose and Cholesterol}

Serum creatinine was estimated by Jaffes method [33]. Serum creatinine in alkaline medium reacts with picrate to produce an orange color that absorbs light at $492 \mathrm{~nm}$. The rate of increase in absorbance is directly proportional to the concentration of creatinine in specimen. Blood glucose was measured by employing enzymatic method [34].

Serum cholesterol was measured [35]. In the former, glucose oxidase converts glucose to gluconic acid, yielding hydrogen peroxide $\left(\mathrm{H}_{2} \mathrm{O}_{2}\right)$. Cholesterol esterase hydrolyses cholesterol esters into free cholesterol and fatty acids, and cholesterol oxidase then converts the cholesterol to $\mathrm{H}_{2} \mathrm{O}_{2}$ and cholest-4-en-3 one. $\mathrm{H}_{2} \mathrm{O}_{2}$ in the presence of peroxidase oxidatively couples with 4-aminoantipyrine and phenol to produce a red quinoneimine dye, having an absorbance maximum at $510 \mathrm{~nm}$. The intensity of the red color is proportional to the amount glucose or total cholesterol in the specimen, respectively. Hematologic parameters were measured by using a fully automated Hematology analyzer Sysmax K-4500 [36]. 


\subsection{Identification of Neuro-cognitive Impairment}

To identify high-risk subjects for neuro-cognitive impairment, we used the Iranian version of SNI. This self-report inventory contains 76 questions about everyday memory and attention problems. Subjects had to answer each question on a five-point Likert scale from "very frequently" to "never". The questions covered selective attention (ten items), divided attention (four items), long-term memory (seven items), prospective memory (seven items), and psychomotor retardation (nine items). The GHQ-28 was also used to identify the following four symptoms in the high-risk subjects: "somatic symptoms", "anxiety and insomnia", "social dysfunction", and "severe depression".

\section{STATISTICAL ANALYSIS}

To compare pesticide sprayers and control data, we used the two-sided forms of Mann-Whitney U and Student's ttests. The association between variables was established using Spearman's correlation coefficient. All data, except for demographic, are presented as median and quartiles or mean \pm SD. The $\mathrm{p}$ values lower than 0.05 were considered statistically significant. The analysis was run on Stats Direct version 2.7.9.

\section{RESULTS}

OPs pesticide sprayers and controls did not significantly differ in age. The controls smoked for significantly longer than farmers even though the amount of cigarettes/Bidi smoked did not differ significantly (Table 1).

Table 2 shows the somatic symptoms, anxiety and insomnia, social dysfunction, and severe depression in sprayers and controls. The rates of anxiety and insomnia $(p=0.030)$ and severe depression $(p<0.001)$ were significantly higher in the OPs pesticide sprayers than controls, while the rate of social dysfunction was significantly lower than in controls $(p<0.001)$.

Table 2. The status of mental health in pesticide sprayers and controls.

\begin{tabular}{|l|c|c|c|c|c|}
\hline \multicolumn{1}{|c|}{ Group } & Somatic Symptoms & Anxiety \& insomnia & Social dysfunction & Severe depression & GHQ-28 \\
\hline Control (n=187) & $7(6$ to 7$)$ & $7(4$ to 7$)$ & $7(7$ to 7$)$ & 3 (0 to 7$)$ & $24(19$ to 28$)$ \\
\hline Sprayers (n=187) & $7(4$ to 10$)$ & $8(4$ to 11$)$ & $6(4$ to 8$)$ & $5.5(2$ to 9.25$)$ & $26.5(16.75$ to 37.25$)$ \\
\hline$* \boldsymbol{p}$ value & 0.907 & 0.030 & 0.002 & 0.0001 & 0.060 \\
\hline
\end{tabular}

Data represent median and quartiles (Q1-Q3). GHQ-28: General Health Questionnaire-28. *Two-sided Mann-Whitney U test.

Table 3 shows that psychomotor speed (PS), selective attention (SA), divided attention (DA), verbal memory (VM), nonverbal memory (NVM), prospective memory (PM), spatial functioning (SF), and initiative/energy (I/E) were significantly lower in sprayers than controls $(p<0.001)$.

Table 3. Neuro-cognitive impairment in controls and pesticide sprayers.

\begin{tabular}{|l|c|c|c|}
\hline & $\begin{array}{c}\text { Controls } \\
(\mathbf{n = 1 8 7 )}\end{array}$ & $\begin{array}{c}\text { Sprayers } \\
\text { (n=187) }\end{array}$ & $\boldsymbol{p}$ Value* \\
\hline Psychomotor speed (PS) & $31(29$ to 34$)$ & $23(19$ to 28$)$ & $<0.001$ \\
\hline Selective attention (SA) & $44(40.5$ to 47$)$ & $29.5(24$ to 35) & $<0.001$ \\
\hline Divided attention (DA) & $18(17$ to 19$)$ & $14(10.25$ to 17.75$)$ & $<0.001$ \\
\hline Verbal memory (VM) & $35(32$ to 38.5$)$ & $26.5(20.25$ to 32$)$ & $<0.001$ \\
\hline Nonverbal memory (NVM) & $18(16$ to 20$)$ & $14.5(11$ to 16$)$ & $<0.001$ \\
\hline Prospective memory (PM) & $31(29$ to 34$)$ & $23(20$ to 28$)$ & $<0.001$ \\
\hline Spatial functioning (SF) & $18(16$ to 20$)$ & $14(11$ to 17$)$ & $<0.001$ \\
\hline Initiative/energy (I/E) & $48(45$ to 51$)$ & $35(28.25$ to 43$)$ & $<0.001$ \\
\hline Total & $333(309$ to 353$)$ & $244.5(211.25$ to 286.5$)$ & $<0.001$ \\
\hline
\end{tabular}

Data represent the median and quartiles (Q1-Q3). *Two-sided Mann-Whitney U test.

Table 4 shows haematological parameters in the two groups. Median FBG $(p<0.001)$, BUN $(p=0.014)$, CL $(p<0.001)$, and oral GTT $(p<0.001)$ were significantly higher in pesticide sprayers than controls, whereas AST $(p<0.001)$, ALP $(p<0.001)$, and creatinine $(p=0.008)$ were significantly lower than in controls.

There was a positive correlation between the number of working years on one side and eczema $(\mathrm{r} 2=0.403, p<0.001)$, saliva secretion $(\mathrm{r} 2=0.307, p<0.001)$, fatigue $(\mathrm{r} 2=0.433, p<0.001)$, headache $(\mathrm{r} 2=0.472, p<0.001)$, sweating $(\mathrm{r} 2=0.343$, $p<0.001$ ), abdominal pain ( $\mathrm{r} 2=0.235, p<0.001)$, nausea $(\mathrm{r} 2=0.265, p<0.001)$, superior distal muscle weakness $(\mathrm{r} 2=0.215$, $p<0.001$ ), inferior distal muscle weakness $(\mathrm{r} 2=0.196, p<0.001)$, inferior proximal muscle weakness $(\mathrm{r} 2=0.166$, 
$p<0.004)$, breath muscle weakness ( $\mathrm{r} 2=0.138, p<0.017)$, hand tingling ( $\mathrm{r} 2=0.438, p<0.001)$, foot tingling ( $\mathrm{r} 2=0.435$, $p<0.001$ ), epiphoria ( $\mathrm{r} 2=0.279, p<0.001)$, polyuria $(\mathrm{r} 2=0.210, p<0.001)$, miosis $(\mathrm{r} 2=0.202, p<0.001)$, dyspnoea ( $\mathrm{r} 2=0.345, p<0.001)$, bradycardia ( $\mathrm{r} 2=0.191, p<0.001)$, and nasal flowing $(\mathrm{r} 2=0.311, p<0.001)$ on the other. The interviews clearly showed that only $2.67 \%$ of the pesticide sprayers used proper protection at work such as masks.

Table 4. Haematological parameters in pesticide sprayers and controls.

\begin{tabular}{|c|c|c|c|}
\hline & $\begin{array}{c}\text { Controls } \\
(\mathrm{n}=187)\end{array}$ & $\begin{array}{c}\text { Sprayers } \\
(\mathrm{n}=187)\end{array}$ & p Value* \\
\hline FBG (mg/dL-1) & $\begin{array}{c}78.31 \\
\text { (62 to } 84)\end{array}$ & $\begin{array}{c}84.90 \\
\text { (76.25 to } 94)\end{array}$ & 0.001 \\
\hline BUN (mg/dL-1) & $\begin{array}{c}28.99 \\
\text { (23 to } 34)\end{array}$ & $\begin{array}{c}31.02 \\
(23 \text { to } 38)\end{array}$ & 0.014 \\
\hline Creatinine (mg/dL-1) & $\begin{array}{c}0.87 \\
(0.8 \text { to } 0.9)\end{array}$ & $\begin{array}{c}0.83 \\
(0.7 \text { to } 0.9)\end{array}$ & 0.008 \\
\hline CL (mg/dL-1) & $\begin{array}{c}160.61 \\
(143 \text { to } 180.75)\end{array}$ & $\begin{array}{c}174.5 \\
\text { (151 to } 194.5)\end{array}$ & 0.001 \\
\hline TG (mg/dL-1) & $\begin{array}{c}138.73 \\
(79.25 \text { to } 170.75)\end{array}$ & $\begin{array}{c}123.59 \\
\text { (79 to } 157.75 \text { ) }\end{array}$ & 0.77 \\
\hline HDL (mg/dL-1) & $\begin{array}{c}47.42 \\
\text { (40 to } 54)\end{array}$ & $\begin{array}{c}44.85 \\
(40 \text { to } 50)\end{array}$ & 0.051 \\
\hline AST (IU/L-1) & $\begin{array}{c}31.31 \\
\text { (25 to } 34.75)\end{array}$ & $\begin{array}{c}24.52 \\
(18 \text { to } 29)\end{array}$ & 0.001 \\
\hline ALT (IU/L-1) & $\begin{array}{c}20.82 \\
(15 \text { to } 25)\end{array}$ & $\begin{array}{c}20.19 \\
(12 \text { to } 24)\end{array}$ & 0.108 \\
\hline ALP (IU/L-1) & $\begin{array}{c}113.74 \\
\text { (92 to } 131 \text { ) }\end{array}$ & $\begin{array}{c}93.14 \\
(73.25 \text { to } 109)\end{array}$ & 0.001 \\
\hline Oral GTT (mg/dL-1) & $\begin{array}{c}68.43 \\
(70 \text { to } 100)\end{array}$ & $\begin{array}{c}86.27 \\
\text { (79 to } 95)\end{array}$ & 0.001 \\
\hline
\end{tabular}

Data represent median and quartiles (Q1-Q3). *Two-sided Mann-Whitney U test FBG- fasting blood glucose, BUN- blood urea nitrogen, CLcholesterol, TG- triglycerides, HDL- high-density lipoprotein, AST- aspartate aminotransferase, ALT- alanine, aminotransferase, ALP- alkaline phosphatase, GTT-glucose tolerance test.

\section{DISCUSSION}

As compared to controls, pesticide sprayers in this study have shown significantly higher neuro-cognitive impairment, psychological distress, and FBG, BUN, CL, and oral GTT levels and significantly lower AST, ALP, and creatinine. These findings suggest that exposure to OPs resulted in a sort of toxicity in the OP pesticide sprayers, especially as there is a positive correlation between years of work and clinical symptoms. Interviews with the sprayers have shown that they did not use proper protection like masks, gloves, long boots, head cover, or face cover, and that they did not shower regularly, even though showers were available. The only safety they used was a kind of cloth mask. Our findings support a significant positive correlation between working history and clinical symptoms in pesticide sprayers found by Singh et al. [37] in organ systems such as the respiratory, ocular, gastrointestinal, and skin. Sprayers also complained of pesticide poisoning symptoms. They showed a marked rise in neuro-cognitive impairment and psychological distress reported an association between low-level pesticide exposure and deficits in neurobehavioral performance. The exposure to low pesticide levels over many years in agriculture is associated with neurological impairment parameters such as selective attention, symbol and digit, and reaction time [38, 39]. Moreover, Singh et al. [37] claim to provide powerful evidence of the causal relationship between OP exposure and neuropsychiatric disorders, including mood destabilization and cognitive impairment. In fact, many studies report higher incidence of neuropsychological disorders in OP exposed workers [40,41] through oxidative stress and consequent apoptotic neuronal cell death [3]. OPs also induce neuro-cognitive disorders by inhibiting the activity of NTE acylpeptide hydrolase [22, 23]. Our finding of increased FBG is in agreement with an earlier study in sprayers chronically exposed to OPs [42]. Alonso Magdalena et al. [43] reported that small doses of bisphenol-A affected glucose metabolism in rodents which suggests that a change in glucose homeostasis may cause type 2 diabetes. This imbalance might also be caused by low-dose OP exposure through endocrine disorder [37]. Various OPs can contribute to the development of obesity, dyslipidaemia, and insulin resistance - common precursors of type 2 diabetes and cardiovascular diseases [44 47]. Recently, Pakzad et al. [48] and Lee et al. [49] reported that diazinon disturbs glucose homeostasis in adipose tissues through oxidative stress. All these findings make a point that OPs put glucose out of balance; they may induce diabetes by stimulating hepatic gluconeogenesis and glycogenolysis or disruption of insulin effects in peripheral organs 
[9]. The present study has confirmed that pesticide sprayers are prone to neuropsychological disorders and diabetes caused by OP exposure. Future studies should be investigating the effects of natural antioxidants in OP-exposed sprayers in the hope that they can lessen OP toxicity. The toxic effect of pesticides on the occupational sprayer is a serious issue and precautionary measures must be taken to ameliorate their health status. The regulatory and monitoring system must be strict and effective to meet the challenge of indiscriminate use of lethal pesticides.

\section{CONFLICT OF INTEREST}

The authors confirm that this article content has no conflicts of interest.

\section{ACKNOWLEDGEMENTS}

The authors thank the facilities provided by IITR, Lucknow and Dr. Ram Manohar Lohia Avadh University, Faizabad to carry out this investigation.

\section{REFERENCES}

[1] Quazi, S.H.; Jamal, F.; Rastogi, S.K. Effect of organo-phosphorus on biochemical parameters on agricultural workers. Asian J. Biochem., 2012, 7(1), 37-45. [http://dx.doi.org/10.3923/ajb.2012.37.45]

[2] Indira, D.P.; Bellamy, R.; Sunder, P.S. Facing hazards at work-Agricultural workers and pesticide exposure in Kuttanad. Kerala. SANDEE, 2007, 19(7), 1-4.

[3] W. H. O. Preventing Intentional and Unintentional Deaths from Pesticide Poisoning, The Impact of pesticides on Health, 2004 [Accessed on: 5 Feb 2015]; Available at: http://www.who.int/mental_health/prevention/suicide/en/PesticidesHealth2.pdf

[4] Jeyaratnam, J. Acute pesticide poisoning: a major global health problem. World Health Stat. Q., 1990, 43(3), $139-144$. [PMID: 2238694]

[5] Abdollahi, M.; Ranjbar, A.; Shadnia, S.; Nikfar, S.; Rezaie, A. Pesticides and oxidative stress: a review. Med. Sci. Monit., 2004, 10(6), RA141-RA147. [PMID: 15173684]

[6] Jamshidi, H.R.; Ghahremani, M.R.; Ostad, S.N.; Sharifzadeh, M.; Dehpour, A.R.; Abdollahi, M. Effects of diazinon on the activity and gene expression of mitochondrial glutamate dehydrogenase from rat pancreatic Langerhans islets. Pestic. Biochem. Physiol., 2009, 93(1), $23-27$. [http://dx.doi.org/10.1016/j.pestbp.2008.09.002]

[7] Shadnia, S.; Dasgar, M.; Taghikhani, S.; Mohammadirad, A.; Khorasani, R.; Abdollahi, M. Protective effects of alphatocopherol and n-acetylcysteine on diazinon-induced oxidative stress and acetylcholinesterase inhibition in rats. Toxicol. Mech. Methods, 2007, 17(2), 109-115. [http://dx.doi.org/10.1080/15376510600860318] [PMID: 20020979]

[8] Rahimi, R.; Nikfar, S.; Abdollahi, M. Increased morbidity and mortality in acute human organophosphate-poisoned patients treated by oximes: a meta-analysis of clinical trials. Hum. Exp. Toxicol., 2006, 25(3), 157-162. [http://dx.doi.org/10.1191/0960327106ht602oa] [PMID: 16634335]

[9] Mohammadi, H.; Karimi, G.; Shafiee, H.; Nikfar, S.; Baeeri, M.; Sabzevari, O.; Abdollahi, M.; Sabzevari, O.; Abdollahi, M. Benefit of nanocarrier of magnetic magnesium in rat malathion-induced toxicity and cardiac failure using non-invasive monitoring of electrocardiogram and blood pressure. Toxicol. Ind. Health, 2011, 27(5), 417-429. [http://dx.doi.org/10.1177/0748233710387634] [PMID: 21310777]

[10] Saadi, H.S.; Abdollahi, M. The importance of pesticides effects on human reproduction in farmers. Int. J. Pharmacol., 2012, 8(46), 7-9.

[11] Pournourmohammadi, S.; Ostad, S.N.; Azizi, E.; Ghahremani, M.H.; Farzami, B.; Minaie, B.; Larijani, B.; Abdollahi, M. Induction of insulin resistance by malathion: Evidence for disrupted islets cells metabolism and mitochondrial dysfunction. Pestic. Biochem. Physiol., 2007, 88(3), 346-352.

[http://dx.doi.org/10.1016/j.pestbp.2007.02.001]

[12] Soltaninejad, K.; Abdollahi, M. Current opinion on the science of organophosphate pesticides and toxic stress: a systematic review. Med. Sci. Monit., 2009, 15(3), RA75-RA90.

[PMID: 19247260]

[13] Mostafalou, S.; Eghbal, M.A.; Nili-Ahmadabadi, A.; Baeeri, M.; Abdollahi, M. Biochemical evidence on the potential role of organophosphates in hepatic glucose metabolism toward insulin resistance through inflammatory signaling and free radical pathways. Toxicol. Ind. Health, 2012, 28(9), 840-851.

[http://dx.doi.org/10.1177/0748233711425073] [PMID: 22082825]

[14] Rahimi, R.; Nikfar, S.; Larijani, B.; Abdollahi, M. A review on the role of antioxidants in the management of diabetes and its complications. Biomed. Pharmacother., 2005, 59(7), 365-373.

[http://dx.doi.org/10.1016/j.biopha.2005.07.002] [PMID: 16081237]

[15] Panahi, P.; Vosough-Ghanbari, S.; Pournourmohammadi, S.; Ostad, S.N.; Nikfar, S.; Minaie, B.; Abdollahi, M. Stimulatory effects of malathion on the key enzymes activities of insulin secretion in langerhans islets, glutamate dehydrogenase and glucokinase. Toxicol. Mech. 
Methods, 2006, 16(4), 161-167.

[http://dx.doi.org/10.1080/15376520500191623] [PMID: 20021041]

[16] Amirkabirian, N.; Teimouri, F.; Esmaily, H.; Mohammadirad, A.; Aliahmadi, A.; Abdollahi, M. Protection by pentoxifylline of diazinoninduced toxic stress in rat liver and muscle. Toxicol. Mech. Methods, 2007, 17(4), 215-221. [http://dx.doi.org/10.1080/15376510600943783] [PMID: 20020971]

[17] Vosough-Ghanbari, S.; Sayyar, P.; Pournourmohammadi, S.; Aliahmadi, A.; Ostad, S.N.; Abdollahi, M. Stimulation of insulin and glucagon synthesis in rat Langerhans islets by malathion in vitro: Evidence for mitochondrial interaction and involvement of subcellular noncholinergic mechanisms. Pestic. Biochem. Physiol., 2007, 89(2), 130-136. [http://dx.doi.org/10.1016/j.pestbp.2007.05.001]

[18] Pourkhalili, N.; Pournourmohammadi, S.; Rahimi, F. VosoughGhanbari, S.; Baeeri, M.; Ostad, S.N.; Abdollahi, M. Comparative effects of calcium channel blockers, autonomic nervous system blockers, and free radical scavengers on diazinon-induced hyposecretion of insulin from isolated islets of Langerhans in rats. Arch. Indust. Hyg. Toxicol., 2009, 60(2), 57-64.

[19] Bayrami, M.; Hashemi, T.; Malekirad, A.A.; Ashayeri, H.; Faraji, F.; Abdollahi, M. Electroencephalogram, cognitive state, psychological disorders, clinical symptom, and oxidative stress in horticulture farmers exposed to organophosphate pesticides. Toxicol. Ind. Health, 2012, 28(1), 90-96.

[http://dx.doi.org/10.1177/0748233711407243] [PMID: 21632574]

[20] Abdollahi, M.; Karami-Mohajeri, S. A comprehensive review on experimental and clinical findings in intermediate syndrome caused by organophosphate poisoning. Toxicol. Appl. Pharmacol., 2012, 258(3), 309-314.

[http://dx.doi.org/10.1016/j.taap.2011.11.014] [PMID: 22177963]

[21] Ranjbar, A.; Ghahremani, M.H.; Sharifzadeh, M.; Golestani, A.; Ghazi-Khansari, M.; Baeeri, M.; Abdollahi, M. Protection by pentoxifylline of malathion-induced toxic stress and mitochondrial damage in rat brain. Hum. Exp. Toxicol., 2010, 29(10), $851-864$. [http://dx.doi.org/10.1177/0960327110363836] [PMID: 20194575]

[22] Rezvanfar, M.A.; Rezvanfar, M.A.; Ranjbar, A.; Baeeri, M.; Mohammadirad, A.; Abdollahi, M. Biochemical evidence on positive effects of rolipram a phosphodiesterase-4 inhibitor in malathion induced toxic stress in rat blood and brain mitochondria. Pestic. Biochem. Physiol., 2010, 98, 135-143.

[http://dx.doi.org/10.1016/j.pestbp.2010.06.001]

[23] Karami-Mohajeri, S.; Abdollahi, M. Toxic influence of organophosphate, carbamate, and organochlorine pesticides on cellular metabolism of lipids, proteins, and carbohydrates: a systematic review. Hum. Exp. Toxicol., 2011, 30(9), 1119-1140. [http://dx.doi.org/10.1177/0960327110388959] [PMID: 21071550]

[24] Abdollahi, M.; Donyavi, M.; Pournourmohammadi, S.; Saadat, M. Hyperglycemia associated with increased hepatic glycogen phosphorylase and phosphoenolpyruvate carboxykinase in rats following subchronic exposure to malathion. Comp. Biochem. Physiol. Toxicol. Pharmacol. Part C, 2004, 137, 343-347.

[25] Rahimi, R.; Abdollahi, M. A review on the mechanisms involved in hyperglycemia induced by organophosphorus pesticides. Pestic. Biochem. Physiol., 2007, 88, 115-121. [http://dx.doi.org/10.1016/j.pestbp.2006.10.003]

[26] Shafiee, H.; Mohammadi, H.; Rezayat, S.M.; Hosseini, A.; Baeeri, M.; Hassani, S.; Mohammadirad, A.; Bayrami, Z.; Abdollahi, M. Prevention of malathion-induced depletion of cardiac cells mitochondrial energy and free radical damage by a magnetic magnesium-carrying nanoparticle. Toxicol. Mech. Methods, 2010, 20(9), 538-543.

[http://dx.doi.org/10.3109/15376516.2010.518173] [PMID: 20919798]

[27] Pancetti, F.; Olmos, C.; Dagnino-Subiabre, A.; Rozas, C.; Morales, B. Noncholinesterase effects induced by organophosphate pesticides and their relationship to cognitive processes: implication for the action of acylpeptide hydrolase. J. Toxicol. Environ. Health B Crit. Rev., 2007, $10(8), 623-630$.

[http://dx.doi.org/10.1080/10937400701436445] [PMID: 18049927]

[28] Jokanović, M.; Kosanović, M. Neurotoxic effects in patients poisoned with organophosphorus pesticides. Environ. Toxicol. Pharmacol., 2010, 29(3), 195-201.

[http://dx.doi.org/10.1016/j.etap.2010.01.006] [PMID: 21787602]

[29] Knedel, B.; Boettger, R.; Klin, W. Arbeitsgruppe enzyme der Deutschon Gesellschall fur. Klinische Chemie, 1967, 20 , $123-124$.

[30] Recommended methods for the determination of four enzymes in blood. Scand. J. Clin. Lab. Invest., 1974, 33(4), $291-306$. [http://dx.doi.org/10.3109/00365517409082499] [PMID: 4369123]

[31] Varley, H. Practical Clinical Biochemistry, $4^{\text {th }}$ ed; William Heinemann Medical Books: Ammanford, United Kingdom, 1975 , p. 453.

[32] Kassirer, J.P. Clinical evaluation of kidney function-glomerular function. N. Engl. J. Med., 1971, 285(7), 385-389. [http://dx.doi.org/10.1056/NEJM197108122850706] [PMID: 4933769]

[33] Larsen, K. Creatinine assay by a reaction-kinetic principle. Clin. Chim. Acta, 1972, 41, 209-217. [http://dx.doi.org/10.1016/0009-8981(72)90513-X] [PMID: 4645233]

[34] Young, D.S.; Pestaner, L.C.; Gibberman, V. Effects of drugs on clinical laboratory tests. Clin. Chem., 1975, 21(5), 1D-432D. [PMID: 1091375]

[35] Allain, C.C.; Poon, L.S.; Chan, C.S.; Richmond, W.; Fu, P.C. Enzymatic determination of total serum cholesterol. Clin. Chem., 1974, 20(4), 
470-475.

[PMID: 4818200]

[36] Schmidt-Kehl, L. Blood changes in chronic lead poisoning. Arch Für. Hyg., 1927, 98, 1-22.

[37] Singh, V.K.; Jyoti, ; Reddy, M.M.; Kesavachandran, C.; Rastogi, S.K.; Siddiqui, M.K. Biomonitoring of organochlorines, glutathione, lipid peroxidation and cholinesterase activity among pesticide sprayers in mango orchards. Clin. Chim. Acta, 2007, 377(1-2), 268-272. [http://dx.doi.org/10.1016/j.cca.2006.08.037] [PMID: 17067563]

[38] Moritz, S.; Ferahli, S.; Naber, D. Memory and attention performance in psychiatric patients: lack of correspondence between clinician-rated and patient-rated functioning with neuropsychological test results. J. Int. Neuropsychol. Soc., 2004, 10(4), 623-633. [http://dx.doi.org/10.1017/S1355617704104153] [PMID: 15327740]

[39] Messner, C.; Poser, U.; Sedelmeier, P. Ein fragebogen erlebter defizite der D. Goldbeg and P. A. Williams, “A User's Guide to the General Health Questionnaire; National Foundation for Educational Research: Windsor, 1998.

[40] Zimmermann aufmerksamkeit, P. (FEDA) [A questionnaire measuring self-experienced deficits of attention, in German]. Freiburg Psychologisches Institute der Albert-Ludwigs University, 1991.

[41] Rothlein, J.; Rohlman, D.; Lasarev, M.; Phillips, J.; Muniz, J.; McCauley, L. Organophosphate pesticide exposure and neurobehavioral performance in agricultural and non-agricultural Hispanic workers. Environ. Health Perspect., 2006, 114(5), $691-696$. [http://dx.doi.org/10.1289/ehp.8182] [PMID: 16675422]

[42] Davies, D.R.; Mrcpsych, M.; Ahmed, G.M.; Freer, T. Chronic organophosphate induced neuropsychiatric disorder (COPIND): Results of two postal questionnaire surveys. J. Nutr. Environ. Med., 1999, 9, 123-134. [http://dx.doi.org/10.1080/13590849961726]

[43] Alonso-Magdalena, P.; Ropero, A.B.; Soriano, S.; Quesada, I.; Nadal, A. Bisphenol-A: a new diabetogenic factor? Hormones (Athens), 2010, 9(2), 118-126. [PMID: 20687395]

[44] Rosenstock, L.; Keifer, M.; Daniell, W.E.; McConnell, R.; Claypoole, K. Chronic central nervous system effects of acute organophosphate pesticide intoxication. Lancet, 1991, 338(8761), 223-227. [http://dx.doi.org/10.1016/0140-6736(91)90356-T] [PMID: 1676786]

[45] Fiedler, N.; Kipen, H.; Kelly-McNeil, K.; Fenske, R. Long-term use of organophosphates and neuropsychological performance. Am. J. Ind. Med., 1997, 32(5), 487-496. [http://dx.doi.org/10.1002/(SICI)1097-0274(199711)32:5<487::AID-AJIM8>3.0.CO;2-P] [PMID: 9327072]

[46] Rezg, R.; Mornagui, B.; Kamoun, A.; El-Fazaa, S.; Gharbi, N. Effect of subchronic exposure to malathion on metabolic parameters in the rat. C. R. Biol., 2007, 330(2), 143-147.

[http://dx.doi.org/10.1016/j.crvi.2006.11.002] [PMID: 17303541]

[47] Lee, D-H.; Steffes, M.W.; Sjödin, A.; Jones, R.S.; Needham, L.L.; Jacobs, D.R., Jr. Low dose of some persistent organic pollutants predicts type 2 diabetes: a nested case-control study. Environ. Health Perspect., 2010, 118(9), 1235-1242. [http://dx.doi.org/10.1289/ehp.0901480] [PMID: 20444671]

[48] Pakzad, M.; Fouladdel, S.; Nili-Ahmadabadi, A.; Pourkhalili, N.; Baeeri, M.; Azizi, E.; Sabzevari, O.; Ostad, S.N.; Abdollahi, M. Sublethal exposures of diazinon alters glucose homostasis in Wistar rats: Biochemical and molecular evidences of oxidative stress in adipose tissues. Pestic. Biochem. Physiol., 2013, 105(1), 57-61.

[http://dx.doi.org/10.1016/j.pestbp.2012.11.008] [PMID: 24238291]

[49] Lee, D-H.; Steffes, M.W.; Sjödin, A.; Jones, R.S.; Needham, L.L.; Jacobs, D.R., Jr. Low dose organochlorine pesticides and polychlorinated biphenyls predict obesity, dyslipidemia, and insulin resistance among people free of diabetes. PLoS One, 2011, 6(1), e15977. [http://dx.doi.org/10.1371/journal.pone.0015977] [PMID: 21298090]

(C) Jamal et al.; Licensee Bentham Open.

This is an open access article licensed under the terms of the Creative Commons Attribution-Non-Commercial 4.0 International Public License (CC BY-NC 4.0) (https://creativecommons.org/licenses/by-nc/4.0/legalcode), which permits unrestricted, non-commercial use, distribution and reproduction in any medium, provided the work is properly cited. 